\title{
A família: um recurso para a intervenção social em períodos de incerteza
}

\author{
Jorge M. L. Ferreira \\ ISCTE - Instituto Universitário de Lisboa \\ Maria João Pena \\ ISCTE - Instituto Universitário de Lisboa
}

Resumo

Neste artigo refletimos sobre o papel da ação social na promoção de bem-estar em períodos de crise e no presente, durante o período pandémico. O exercício do Serviço Social na sociedade é aplicado por assistentes sociais que, embora seja um recurso especializado, tem uma fraca autonomia do profissional na tomada de decisão, um fraco reconhecimento do saber teórico do assistente social pelos decisores institucionais e trabalha maioritariamente em equipas uniprofissionais. Mas o assistente social sendo um profissional especializado tem uma formação teórico-prática sustentada na aquisição de competências teóricas, instrumentais e práticas para uma intervenção na complexidade, incluindo o trabalho em rede e a advocacia e o treino da observação da realidade social em que a pessoa se insere. O assistente social, como profissional da relação e da comunicação, desempenha uma forte atividade de mediação na conexão dos diferentes agentes para uma mudança social sustentável.

Na elaboração do artigo utilizamos uma metodologia qualitativa baseada em técnicas de observação da realidade social ao nível institucional e comunitário, de pesquisa e análise documental.

O artigo instiga à reflexão profissional, à inovação das abordagens de intervenção e a uma nova matriz de pensar a ação social emancipatória e promotora de maior inclusão social numa forte e efetiva aplicação de direitos humanos para o desenvolvimento social e humano. Destacamos a necessidade das intervenções públicas na prossecução de objetivos coletivos fundamentados numa estratégia de desenvolvimento que promova um futuro mais sustentável e equitativo. Se, por um lado, a pandemia veio salientar a necessidade de políticas mais equitativas e sustentáveis, baseadas no diálogo social, e igualmente importante alargar a reflexão sobre a proteção social a domínios como a regulamentação do teletrabalho e promover uma maior disponibilidade da sociedade para mobilizar recursos financeiros, contribuindo para a minimização de riscos através da Segurança Social e aumentar a confiança do público nas instituições sociais.

\section{Palavras-chave}

Crise; Família; Serviço Social; Ação Social; Abordagens colaborativas

Códigos JEL: D78, 138, J16, J71, K38, Z18

\author{
THE FAMILY: A RESOURCE FOR SOCIAL INTERVENTION IN TIMES OF \\ UNCERTAINTY
}

Abstract

In this article we reflect on the role of social action in promoting well-being in periods of crisis and in the present, during pandemic period. The exercise of Social Work in society is applied by social workers who, despite being a specialised resource, have little professional autonomy in decision-making, little recognition of the theoretical knowledge of the social worker by institutional decisionmakers and work mostly in single-professional teams. However, as a specialised professional, the social worker has a theoretical and practical training sustained by the acquisition of theoretical, instrumental, and practical skills for an intervention in complexity. including networking and social advocacy, as well as training in the observation of the social reality in which the person is inserted. The social worker, as a relationship and communication professional, performs a strong mediating activity in connecting the different agents for a sustainable social change.

In preparing the article we used a qualitative methodology based on techniques of observation of social reality at the institutional and community level, of research and document analysis.

The article instigates professional reflection, innovation of intervention approaches and a new matrix of thinking about emancipatory social action promoting greater social inclusion in a strong and effective application of human rights for social and human development. We highlight the need for public interventions in the pursuit of collective goals based on a development strategy that promotes a more sustainable and equitable future. If, on the one hand, the pandemic has highlighted the need for more equitable and sustainable policies based on social dialogue, it is equally important to broaden the reflection on social protection to areas such as the regulation of telework and to promote greater willingness of society to mobilise financial resources, contributing to risk minimisation through social security and increasing public confidence in social institutions.

Keywords

Crisis; Family; Social Work; Social Action; Collaborative Approaches

JEL codes: D78, I38, J16, J71, K38, Z18

Fecha de recepción del original: 30 de julio de 2021; versión definitiva: 28 de diciembre de 2021.

Jorge M. L. Ferreira, ISCTE - Instituto Universitário de Lisboa, Departamento de Ciência Política e Políticas Públicas, Escola de Sociologia e Políticas Públicas, Ava das Forças Armadas, 1649-026 Lisboa.

Tel.: +351 217650290; E-mail: Jorge.Manuel.Ferreira@iscte-iul.pt; ORCID ID: https://orcid.org/0000-0003-4835-242X.

Maria João Pena, ISCTE - Instituto Universitário de Lisboa, Departamento de Ciência Política e Políticas Públicas, Escola de Sociologia e Políticas Públicas, Ava das Forças Armadas, 1649-026 Lisboa.

Tel.: +351 217650266; E-mail: maria_joao_pena@iscte-iul.pt; ORCID ID: https://orcid.org/0000-0003-2215-7554. 


\section{A família: um recurso para a intervenção social em períodos de incerteza}

Jorge M. L. Ferreira

ISCTE - Instituto Universitário de Lisboa

Maria João Pena

ISCTE - Instituto Universitário de Lisboa
1. Introdução

A sociedade contemporânea para além da capacidade de produzir bens, resultantes de uma economia de mercado competitivo, exige inovação social como força motriz da nossa economia e criatividade nas relações sociais e laborais com impacto na vida em comum de cada cidadão. Assim, enfrentamos novas dinâmicas no paradigma social dominante de natureza construtivista (Parton, 2000), levando a produzir conhecimentos úteis para compreender e alterar a realidade social dos sistemas sociais e dos cidadãos. A investigação - ação carateriza-se por uma metodologia que reúne uma diversidade de atores sociais. Os profissionais desempenham na atualidade práticas próativas e emancipatórias baseada no seu saber ontológico e na experiência dos sujeitos de intervenção na compreensão do seu ambiente, co-construindo soluções nos contextos institucional e interinstitucional.

A família tem sido a estrutura privilegiada no desenvolvimento das potencialidades de cada sujeito possibilitando a satisfação das necessidades materiais e afetivas, assim como a aprendizagem das normas e da cultura em que está inserido. Esta conceção sistémica de família remete para as suas funções interna e externa, no sentido de proteção e autonomia dos seus membros, assim como a integração social e cultural (Alarcão e Gaspar, 2007). O conceito não pode ficar restrito aos laços de parentesco, devendo alargar-se às ligações baseadas na confiança, suporte mútuo e um destino comum, tal como mencionado pela OMS (1994) e contemplando uma diversidade de configurações.

A Pandemia Covid 19 veio ter um impacto nas dinâmicas familiares, afetando sobretudo as famílias mais vulneráveis e exigindo aos profissionais uma intervenção holística na resposta multidimensional dos problemas que as afetam num contexto que se privilegie a multidisciplinaridade e articulação interinstitucional. A família tem um papel importante em todo o processo de intervenção constituindo-se como parceira na definição de uma resposta de suporte social na ligação das competências da família e dos recursos do meio, devendo esta parceria ser também fundamentada nas evidências da investigação, constituindo um desafio para a formação, nas suas dimensões ética, técnica e instrumental.

O contexto onde se desenvolveu a intervenção na pandemia apresenta também desafios e novas exigências para a formação, a nível ético, técnico e instrumental, devendo os resultados das diferentes investigações levadas a cabo neste período constituir evidências que, em conjunto com a experiência profissional e o saber dos sujeitos de intervenção desenhem o quadro de intervenção adequado à promoção do bem-estar das famílias mais vulneráveis.

O Serviço Social fundamenta-se num conjunto de princípios e valores humanistas e éticos co construídos através dos vários saberes. Esta dimensão interdisciplinar confere ao Serviço Social uma área de conhecimento para estudar e intervir num objeto complexo requerendo uma abordagem multi-referencial promotora de uma leitura plural (De Robertis, 2007). A ação do Serviço Social abrange uma diversidade de campos de intervenção, incluindo várias formas de abordagem, aconselhamento e intervenção casuística, com grupos e trabalho comunitário, mas também integra equipas de conceção de políticas públicas e sociais.

Na perspetiva emancipatória o Serviço Social desenvolve e apoia estratégias que visam aumentar o índice de bem-estar das pessoas, a sua autoestima e o potencial criativo para desafiar as dinâmicas de poder e estruturais opressivas de injustiças, incorporando, assim, uma intervenção aos níveis: micro, macro e meso. O seu enfoque holístico é universal, mas as prioridades da sua prática variam de acordo com os contextos históricos, culturais, políticos e socioeconómicos de cada país.

\section{A Família no Século XXI}

Ao longo do tempo profissionais e investigadores foram construindo diferentes formas de definir as famílias, tendo subjacente diferentes conceções teóricas na compreensão dos problemas. Uma das conceções dominantes 
foi o conceito de famílias multiproblemáticas, considerando um conjunto de problemas complexos, múltiplos e graves que afetam a família (Sousa, 2005), mas igualmente os conceitos de famílias vulneráveis e famílias multi-desafiadas. Estas famílias são caraterizadas por um conjunto de elementos que, no decorrer do seu percurso de vida, condicionam, inevitavelmente, a sua adaptação e desenvolvimento positivo, nomeadamente:

a) Os progenitores estão frequentemente desempregados ou com trabalhos instáveis em part time;

b) Muitas são famílias monoparentais, normalmente mães solteiras;

c) O rendimento é geralmente baixo, cerca de $70 \%$ do rendimento médio nacional para o tipo de agregado, e algumas famílias estão abaixo do limiar de pobreza, ou seja $60 \%$ do rendimento médio para o tipo de agregado a que pertencem;

d) Um número significativo de progenitores sofreu abusos ou negligência em criança, ou tiveram relações disfuncionais na adolescência, ou mesmo ambos;

e) As relações entre os progenitores, mesmo quando separados, são tensas;

f) Em muitas famílias os progenitores não completaram a escolaridade para além do secundário e sofrem desvantagem na procura de emprego;

g) Os membros da família têm, frequentemente, uma saúde precária, especialmente a nível da saúde mental. São frequentes as doenças crónicas e as deficiências. As crianças sofrem de stress e ansiedade e podem desenvolver problemas comportamentais, dificuldades de aprendizagem, perturbação da hiperatividade com défice atenção. Na puberdade os sintomas podem ser mais pronunciados. As crianças frequentemente têm mais dificuldades na escola;

h) Os progenitores podem ter tido, ou continuar a ter, problemas de consumo de substâncias ou consumo de álcool;

i) As famílias têm, frequentemente, problemas de relação com outros familiares e pouco suporte de amigos, vizinhos e podem estar socialmente isoladas.

Nem todas as famílias com múltiplos desafios são iguais, mas uma família com 4 ou 5 destas características, pode ser considerada multi-desafiada (APCC, 2019). A definição de famílias multi-desafiadas leva à reconfiguração do paradigma de intervenção com famílias, considerando não apenas o problema, mas também as forças da família, apoiando-a nas suas necessidades e promovendo as suas competências.

Todas as pessoas e as famílias possuem forças e capacidades que podem promover para melhorar a qualidade das suas vidas. Há que ativar as competências da família, explorando as alternativas no reportório da família, no sentido de as ajudar a reconhecer as suas próprias capacidades. A perspetiva das Forças surge nos anos 80 do século $X X$, em resposta a uma visão dos profissionais que se concentrava nas deficiências dos utilizadores dos serviços. A uma prática que se concentrava nas patologias e nos problemas das pessoas, esta perspetiva contrapõe que o indivíduo tem potências e forças. Com esta perspetiva passa-se de uma abordagem centrada no problema para uma abordagem baseada na solução. Pode definir-se como Força tudo o que as pessoas sabem acerca do mundo que as rodeia, incluindo o saber intelectual e as experiências de vida (Saleebey, 2002). As qualidades pessoais, os traços de personalidade e todas as virtudes que as pessoas possuem, assim como a própria comunidade possui um conjunto de recursos a nível físico, interpessoal e institucional que embora possam ser mais abundantes em algumas comunidades do que em outras, há sempre recursos que se podem utilizar.

É igualmente importante mencionar a definição de famílias em situação de ansiedade/angústia incluindo as famílias que experimentam simultaneamente vários problemas, que afetam 2 ou mais membros da família assim como diferentes domínios (Evenboer et al., 2018; Tausendfreund et al., 2016; citados por Casado et al., 2020), exigindo um conjunto diferenciado de intervenções que permitam responder aos objetivos assim como uma abordagem multidisciplinar (Casado et al., 2020). Dentro das situações problema encontramos a pobreza, condições de habitação desadequadas, questões conjugais e parentais, adições, atividades antissociais e falta de sistemas de suporte (Bodden and Dekovic, 2016; Chagas, 2014; Imber-Black, 2000; Shamai et al., 2003; citados por Casado et al., 2016). Torna-se fundamental a elaboração de um ecomapa com a família de modo a refletir sobre as relações com todos os profissionais e organizações envolvidas, assim como as relações informais que sejam percebidas como importantes pela família.) Esta construção torna-se igualmente um instrumento para o desenvolvimento de uma relação colaborativa (Imber-Black, 2000, citado por Casado et al., 2020) que permita responder com uma intervenção holística e integrada (Imber-Black, 2000; Sousa e Costa, 2010; citados por Casado et al., 2020).

A intervenção tem como principal objetivo o suporte familiar, entendido como o conjunto de serviços que procuram beneficiar as famílias através do aumento da sua capacidade de cuidar dos seus membros e do fortalecimento das relações familiares, podendo situar-se a nível da prevenção primária, secundária ou terciária, sendo estas duas últimas desenhadas para responder às diferentes vulnerabilidades identificadas, diferenciando-se na intensidade da reparação (Frost e Dolan, 2012). A operacionalização da intervenção exige segundo McCormack (2012):

1- A construção de relações de confiança com a família e a criança que favoreçam a aceitação da intervenção constituindo-se a relação como uma fonte de suporte;

2- O diagnóstico da situação dá-se num contexto de subjetividade, no entanto, é fundamental que o assistente social não imponha os seus valores pessoais aos outros e respeite os valores dos outros; 
3- Importância da articulação interinstitucional, o trabalho em rede, para evitar sobreposições;

4- A intervenção deve ser feita em colaboração com a família, refletindo o seu controle da situação e reduzir o sentimento de impotência;

5- É importante o equilíbrio entre o suporte que é providenciado pelos serviços e a criação de dependência. O objetivo é capacitar as famílias para uma vida independente;

6- O objetivo geral é promover a unidade familiar e ajudar os membros da família a permanecer como família, na medida do possível (McCormack, 2012: 84-86).

Com base na identificação das forças da família a Intervenção constitui-se como global incluindo o meio que rodeia a família, com prioridade às intervenções que promovem a ligação da família aos recursos e a reconstrução das redes de apoio natural, aproximando-se da Preservação Familiar como estratégia de intervenção, definida a partir dos anos 70 do século XX (Rodrigo, 2008). A Preservação Familiar procura promover as competências parentais, o desenvolvimento pessoal e social das figuras parentais e incrementar as fontes de apoio natural, atingindo mudanças na família que melhorem as funções de proteção e educação. Nesta perspetiva uma condição fundamental é a implicação e a responsabilização dos pais na tarefa educativa e o sentido de compromisso (Rodrigo, 2008), sendo necessário estabelecer um clima de colaboração com a família, compreender o ponto de vista da família e as necessidades que expressa, negociar metas a alcançar e os meios e recursos a empregar, fazendo de suporte e facilitador em todo este processo (Rodrigo, 2008). Por outro lado, há que assegurar que o apoio familiar e o acesso a recursos comunitários sejam possíveis para todas as famílias e sobretudo para aquelas que correm maior risco de exclusão social, incluindo a dimensão preventiva que visa promover ações na comunidade que permitam eliminar barreiras do uso dos recursos de apoio às famílias (Rodrigo, 2008). Na perspetiva deste autor, a Preservação Familiar define como objetivos:

$1{ }^{\circ}$ Apoiar as famílias de modo a que possam conservar e reforçar os laços afetivos de modo a dar estabilidade a vida da criança

$2^{\circ}$ Reforçar a função educadora mediante o fortalecimento das competências parentais

$3^{\circ}$ Atender às necessidades específicas das crianças e apoiar as suas competências para favorecer a sua adaptação aos diferentes contextos de desenvolvimento

$4^{\circ}$ Favorecer a autonomia e suficiência da família e de todos os seus membros

$5^{\circ}$ Fortalecer e ampliar os sistemas de apoio naturais da família em combinação com os institucionais $6^{\circ}$ Apoiar as famílias em todas as suas necessidades com a criação de redes comunitárias em que se coordenam múltiplos serviços e eliminam barreiras de utilização

Analisando as competências dos profissionais na intervenção com famílias vulneráveis são diversos os desafios com os quais se cruzam, de natureza ética, teórica, técnica e administrativa. O profissional tem um envolvimento temporário, vai encontrar um grupo (família) que se conhece; "Saltar para um autocarro em movimento" (Coulshed and Orme, 2006). O profissional precisa de ter tempo para conhecer a família e para compreender a dinâmica da família, envolver-se com todos os membros da família e assegurarse que todos participam no desenvolvimento de soluções que serão responsáveis por implementar. Num segundo nível podemos identificar a complexidade de papeis do profissional, em alguns contextos assume diferentes papeis, nomeadamente o de ajuda e de monitorização. "diversidade de agendas". É fundamental que o profissional clarifique a sua pertença institucional, sendo honesto sobre a natureza do seu papel e responsabilidades. Por outro lado, cada vez mais é exigido uma abordagem culturalmente competente, respeitando a diversidade de estruturas familiares em comunidades culturalmente diversas. Ao nível técnico e administrativo é fundamental que os sistemas de registo de informação tenham proteção, que assegurem que os registos eletrónicos ou em papel só possam ser acedidos por algumas pessoas devendo estar disponíveis para a pessoa em causa. Há que definir regras quanto à retenção de informação por parte do profissional e a sua utilização em reuniões de discussão de casos e conferências ou encontros de profissionais (Taylor e Thoburn, 2016).

3. A família e o (s) seu(s) papel (eis) no período de pandemia - COVID 19

«No período COVID 19 - Atuamos mais na reação e menos na pro-ação»

A 2 de março de 2020, Portugal' registou o primeiro caso confirmado de COVID-19, e a primeira morte a 16 de março. A 12 de março, o Governo anunciou o início das medidas de confinamento de largo alcance: foram proibidas deslocações não essenciais e todos os ajuntamentos públicos; as escolas e lojas não essenciais foram encerradas; os movimentos fronteiriços e os voos fortemente restringidos. O estado de emergência foi declarado a 19 de março e renovado duas vezes, tendo terminado a 2 de maio de

\footnotetext{
1 Portugal: Uma análise rápida do impacto da COVID-19 na economia e no mercado de trabalho Autoria/ Ricardo Paes Mamede ISCTE-IUL (coord.) Mariana Pereira OIT-Lisboa António Simões ISCTE-IUL - Organização Internacional do Trabalho, 2020.
} 
2020, substituído pelo estado de calamidade, associado a uma reabertura gradual das atividades económicas e sociais.

Segundo o estudo de Mamede e Pereira (2020), "Quando surgiu a COVID-19 a economia portuguesa tinha recuperado, em larga medida, da crise anterior (a crise económica/financeira de 2008-2012). No final de 2019, o PIB real tinha registado o seu $25 .^{\circ}$ trimestre de expansão ininterrupta. O emprego total tinha aumentado em cada trimestre desde o final de 2013. A taxa de desemprego estava no nível mais baixo desde 2002 ( 6,5 por cento). Os salários reais tinham crescido cerca de 2,7 por cento em 2018 e 2 por cento em 2019, depois de uma década de quase estagnação. [...] Pela primeira vez em 50 anos o saldo orçamental foi positivo, ao mesmo tempo, que a dívida pública, embora ainda elevada, seguia uma tendência claramente descendente" (Mamede e Pereira, 2020: 2).

Neste período pré-covid19, assistíamos em Portugal a uma melhoria da qualidade de vida das pessoas e a um acréscimo de oportunidades de emprego numa diversidade de setores, destacando-se o setor do turismo e da restauração. Oportunidades que se refletiam nos índices de consumo das famílias e na educação/qualificação.

Para Mamede e Pereira (2020) "os principais indicadores de investimento atingiram no primeiro trimestre de 2020 os valores mais elevados desde a viragem do século (especialmente no setor da construção). O setor do turismo depois de quase duplicar o seu peso entre 2014 e 2019, continuou a bater recordes: as receitas na hotelaria tiveram um crescimento de 9,9 por cento nos primeiros dois meses de 2020, em termos homólogos. A produção na indústria transformadora apresentava melhorias desde dezembro de 2019, depois de um comportamento ligeiramente negativo no ano anterior. O desemprego registado teve uma queda de 8,6 por cento em janeiro e de 7,9 por cento em fevereiro face ao mês homólogo do ano anterior" (Mamede e Pereira, 2020: 2).

Impactos COVID na Economia Portuguesa

Vários estudos sugerem que as pessoas mais desfavorecidas têm sido as mais afetadas pela crise. Um inquérito online conduzido em março pelo ISCTE e pelo ICS, dois institutos universitários, concluíram que as pessoas que classificaram a sua situação financeira antes da crise como "difícil" ou "muito difícil" estavam largamente sobre representadas no grupo das que foram financeiramente afetadas pelo confinamento, independentemente do seu nível de qualificação escolar. Outro inquérito online conduzido pela Escola Nacional de Saúde Pública (ENSP) revelou que uma em cada quatro pessoas que auferiam salários abaixo dos 650 euros perderam rendimento, o que compara com 6 por cento nos escalões de rendimento acima dos 2500 euros. Um inquérito mais recente, conduzido pela Universidade Católica Portuguesa, revela que 43 por cento das famílias que ganham até 1000 euros mensais tiveram perda de rendimento, o que compara com 32,6 por cento das que ganham entre 1001-2 500 euros e com 23,4 por cento das que recebem acima de 2500 euros mensais. Embora nenhum destes inquéritos seja estatisticamente representativo, tomados em conjunto fornecem uma visão clara do impacto assimétrico da crise" (Mamede e Pereira, 2020: 9).

Desde o início da pandemia temos assistido a diversos cenários de vida das pessoas orientados por processos de incerteza e de apelo constante a uma cidadania e resiliência de cada cidadão, família e comunidade, bem como a uma ativação efetiva das redes primárias, secundárias e terciárias de apoio e solidariedade.

Continuando a análise dos dados disponíveis verificamos que: "entre o final de fevereiro e o final de abril, o desemprego registado em Portugal, aumentou de cerca de 316000 para 392000 (+24 por cento). Em finais de abril o desemprego registado aumentara cerca de 22,1 por cento, em termos homólogos. Só metade dos trabalhadores afetados estavam cobertos por proteção no desemprego" (Mamede e Pereira, 2020: 3).

Durante os últimos 18 meses de pandemia, muitas pessoas perderam os seus empregos ou foram forçadas a abandonar, o seu emprego para serem cuidadores de descentes e ou ascendentes em casa derivado ao encerramento de escolas, jardins de infância e outros serviços. "A 10 de abril, existiam 170000 beneficiários de uma medida excecional de apoio ao rendimento, destinada a famílias com crianças com menos de 12 anos, e no valor de dois terços do salário bruto, montante nunca inferior ao salário mínimo nacional, podendo chegar a três vezes este valor" (Mamede e Pereira, 2020: 4).

A pandemia veio a acentuar a fragilidade e precarização o emprego para grupos recém-licenciados ou a entrar pela primeira vez no mercado, produzindo também novas adaptações ao modo de vida familiar. "Os contratos temporários são particularmente comuns entre os trabalhadores jovens. Dois terços dos trabalhadores com menos de 25 anos têm relações de trabalho não permanentes (estágios, períodos experimentais, contratos a termo etc.), em comparação com um quinto das pessoas da faixa etária dos 25 a 49 anos e cerca de um décimo dos trabalhadores mais velhos" (Mamede e Pereira, 2020: 8).

Muitas famílias viviam de atividades de economia solidária através de venda de produtos artesanais ou tarefas de cultura e lazer, ou sejam as famílias dependentes da economia informal. Por exemplo grupos étnicos ou de imigrantes instalados em Portugal nomeadamente na agricultura, pesca, serviços domésticos e de limpeza, comércio a retalho, construção e diversas atividades relacionadas com o turismo, setores e áreas de atividade muito afetadas pela pandemia e pelos sucessivos planos de confinamento, embora o Governo Português tenha criado vários programas de proteção social através de subsídios de desemprego e apoio social. Também se afirmou como resposta securisante o Banco Alimentar contra a Fome, uma ONG que presta ajuda alimentar, registou 12000 novos pedidos em abril, abrangendo cerca de 58000 pessoas, um aumento de cerca de 15 por cento face aos níveis pré-pandemia. 
Apresentamos também alguns dados sistematizados pelo BCE macroeconómico/2020 e pelo Eurosistema 2020

Portugal é um país desenvolvido, integrado na União Europeia e com um elevado Índice de Desenvolvimento Humano (IDH) de 0,897 . De acordo com as projeções macroeconómicas do $\mathrm{BCE}^{2}$, a pandemia do coronavírus (COVID-19) tem afetado dramaticamente o mundo e a atividade económica na área do euro desde março de 2020. O PIB da zona euro caiu $11,8 \%$ no segundo trimestre, embora este tenha sido inferior ao esperado nas projeções do Eurosistema de junho de 2020. Como previsões para a recuperação económica, é inicialmente indicada uma concentração na indústria transformadora e em alguns sectores de serviços, enquanto outros sectores, por exemplo, artes, entretenimento, habitação e cultura, continuaram a ser particularmente dificultados. As previsões económicas apontam para uma forte contração do investimento em habitação em 2020, com impactos adversos no acesso à habitação para as famílias com rendimentos mais baixos.

As projeções do Eurosistema (2020), apontam para um aumento da taxa de desemprego e uma queda muito acentuada da força de trabalho, refletindo em parte o facto de alguns trabalhadores que perderam os seus empregos terem sido classificados como "inativos", dadas as reduzidas oportunidades de procurar trabalho durante o período de contingência. Associada a isto está a redução das oportunidades de contratação que terão impacto na Pessoa em termos de consequências para a saúde mental e outros comportamentos sociais inadequados à vida comunitária.

De acordo com o estudo SM-COVID19 - Saúde mental em tempos de pandemia - INRJ ${ }^{3}$

A Pandemia de COVID-19 está a ter impacto na saúde global das populações, nomeadamente na saúde mental, como consequência direta da infeção viral, mas também devido às alterações sociais e económicas resultantes em grande parte das medidas adotadas para controlar a disseminação do vírus na comunidade mundial. Isto decorre de diversos fatores, entre eles, medo e incerteza percecionados pelos indivíduos, medidas de saúde pública adotadas, como o distanciamento físico na sua manifestação mais extrema, como seja o confinamento, consequências socioeconómicas (e.g., perda de rendimento, desemprego).

\footnotetext{
2 BCE para a zona euro/ setembro de 2020 - Banco Central Europeu.

3 Relatório final: SM-COVID19-Saúde mental em tempos de pandemia -Instituto Nacional Dr. Ricardo Jorge (2020).
}

Grupos vulneráveis

Os resultados do estudo revelaram que $33,7 \%$ dos indivíduos da população geral e $44,8 \%$ dos profissionais de saúde apresentavam sinais de sofrimento psicológico. $\mathrm{Na}$ população geral $27 \%$ dos inquiridos reportaram sintomas moderados a graves de ansiedade, $26,4 \%$ de depressão e 26 \% de perturbação de stress pós-traumático. São sobretudo as mulheres, os jovens adultos entre os 18 e os 29 anos, os desempregados e os indivíduos com mais baixo rendimento quem apresenta sintomas de sofrimento psicológico moderado a grave.

Segundo o referido estudo as famílias apresentam maior dificuldade na conciliação trabalho/família e na manutenção dos estilos de vida e atividades de lazer; preocupação com a manutenção do trabalho ou preservação do rendimento; perceção de menos apoio social ou familiar; maior preocupação relativamente ao futuro e menor resiliência.

Numa abordagem mais internacional do problema da pandemia, analisamos alguns dados do relatório INTRUM ${ }^{4}$, 2020

Segundo informações do FMI a pandemia COVID 19, produz um recuo económico global com consequências a longo prazo no bem-estar das famílias a nível internacional embora com impactos diferenciados de acordo com o contexto sócio económico de cada Estado/Nação. Este quadro macroeconómico traz consigo uma complexidade de ansiedades nas famílias e em particular nos agregados familiares com filhos menores de idade. Neste âmbito integram-se os fatores relacionados com as finanças pessoais, à medida que os consumidores (pessoas individuais e famílias) procuram gerir as suas finanças num ambiente alterado e de grande incerteza social e económica no futuro próximo.

A organização INTRUM (Inquiriu 4,800 consumidores em 24 mercados europeus para avaliar o impacto do Covid-19 nas suas finanças bem-estar), com o objetivo de analisar o impacto desta pandemia nas famílias europeias em toda a Europa.

O estudo concluiu que a crise pandémica de base sanitária afetou significativamente o bem-estar financeiro, mas também social e mental das pessoas e das famílias numa relação direta com a fragilidade do emprego e consequente redução de rendimentos dos agregados familiares. Neste estudo de INTRUM/2020, cerca de $48 \%$ dos inquiridos responderem dizendo que o seu bem-estar financeiro di-

\footnotetext{
4 Special Edition White Paper INTRUM, European Consumer Payment Report 2020.
} 
minuiu em comparação com seis meses antes da pandemia, e um terço espera que diminua ainda mais nos próximos seis meses. Apenas $23 \%$, dos inquiridos esperam que melhore" (INTRUM; 2020: 3).

O sentimento de incerteza instalou-se na sociedade muito suportado na ideia do desconhecido que este vírus aporta consigo e pela sua complexidade e versatilidade em se multiplicar em diferentes variantes e cada uma delas traz um novo desafio para a ciência e para o comportamento humano.

Voltando aos dados do inquérito da INTRUM/2020, verificamos que quase 4 em 10 dos inquiridos tiveram o seu emprego afetado por Covid-19, enquanto que $54 \%$ viu um decréscimo de rendimentos no agregado familiar.

Neste contexto pandémico e emergencial surge de forma visível um grupo de famílias mais afetadas pela pandemia, ou sejam os agregados familiares com crianças, sendo que $48 \%$ dos inquiridos disseram que aumentaram as suas preocupações com o aumento das faturas ao nível do consumo de eletricidade, alimentação e água produzindo impactos negativos no seu bem-estar.

Importa realçar a alteração da função CASA, que para muitas famílias deixou de ser apenas um espaço de habitação familiar, para assumir uma diversidade de funções nomeadamente: posto de trabalho (teletrabalho), enfermaria; telescola; lazer; ginásio; espaço de reabilitação e escola de restauração.

Durante a Crise da Covid-19, 63 \% dos agregados familiares com crianças registaram um decréscimo em rendimento, em comparação com $49 \%$ dos agregados familiares sem filhos e $39 \%$ dos agregados familiares com filhos dizem que, depois de pagarem as suas contas, raramente têm o dinheiro suficiente para suportar as despesas referentes aos encargos mensais fixos.

A crise da Covid-19 não produz apenas consequências no imediato na vida das pessoas e das famílias, tem implicações a longo prazo e essas consequências não se reduzem apenas a questões financeiras, abrangem também questões sociais de bem-estar social e de saúde na vida quotidiana das famílias.

Segundo o inquérito da INSTRUM/2020, a crise COVID 19 , trouxe novas preocupações às pessoas e às famílias, em especial às famílias com filhos menores, nomeadamente sobre a questão da poupança familiar, $39 \%$ dos inquiridos dizem estar a poupar significativamente menos dinheiro para o futuro do que estavam a fazer antes do Covid-19. O inquérito também nos facilita um dado importante sobre as expressões do género nas atitudes em relação a poupança: quase metade das mulheres (46\%) dizem não estar confiantes na sua capacidade de poupar para a reforma, em comparação com $34 \%$ homens.

Este dado está alinhado com a informação do Parlamento Europeu, que estimou recentemente que as mulheres na UE ganham, em média cerca de $15 \%$ menos por hora que os homens. São também sub-representadas no mercado de trabalho: quase $30 \%$ das mulheres na UE trabalham a tempo parcial, e as mulheres são mais propensas a deixar de trabalhar para tomar conta de crianças e familiares.

Voltando à CASA, esta também se transformou num espaço de tensão e conflito familiar, nomeadamente em comportamentos de violência doméstica, mau trato e agressões psicológicas e emocionais.

Segundo o departamento europeu da Organização Mundial de Saúde o número de casos de violência doméstica durante o confinamento derivado da pandemia covid-19, aumentou até $60 \%$. (Lusa e PÚBLICO 7 de Maio de 2020, 12:00). Hans Kluge ${ }^{5}$, identificou os países como a Bélgica, Bulgária, França, Irlanda, Federação Russa, Espanha e Reino Unido, com aumento dos casos de "violência interpessoal" entre parceiros íntimos e contra crianças, referindo que o número de chamadas de mulheres vítimas de violência doméstica teve aumentos até $60 \%$ nos países europeus e as denúncias online aumentaram até cinco vezes durante o mês de abril por comparação com os números do mesmo período de 2019.

Realçamos também a precarização das políticas de habitação ampla, de tipologia de família alargada e não apenas orientada para famílias de fratria pequena reduzidas a T1 ou T2 na sua maioria, acessíveis a famílias de classe média e média baixa, cujas consequências se fizeram sentir no período pandémico ao nível de estabilidade, saúde e harmonização das relações familiares.

Na obra editada por Turner (2021) é discutida a experiência de trabalho com crianças, a sua proteção em tempos de pandemia. As questões digitais são analisadas na perspetiva da prática, questionando o impacto da pandemia em problemas que já existiam previamente, nomeadamente doença mental parental, violência doméstica e abuso de substâncias, exacerbados pelo fecho das escolas e pelo isolamento social. As autoras referem os dados da UNICEF (2020) que apontam que durante a pandemia os riscos na proteção à criança aumentaram substancialmente tendo em conta os impactos socioeconómicos no controlo e prevenção das medidas. Os procedimentos na proteção à criança envolvem uma monitorização próxima na forma de contactos face-a-face, de forma regular e numa diversidade de ambientes, incluindo a escola e a morada da família, o que se tornou impossível com as medidas de restrição tomadas durante a pandemia. O próprio ambiente de trabalho em equipa foi afetado, tornando quase impossível as discussões de casos informais e o apoio entre colegas. Por outro lado, a dificuldade de avaliar o risco adequadamente, sem o contacto presencial, apoiando-se nos contactos telefónicos e videochamadas para construir a relação com as famílias.

Se por um lado foram identificados benefícios no trabalho à distância, nomeadamente a flexibilidade no horário, poupança de tempo e dinheiro nas deslocações e a habilidade de influenciar o ambiente de trabalho, há também desvantagens, a dificuldade em separar o trabalho e a vida pessoal e familiar e a possibilidade de ter de partilhar a casa, enquanto espaço de trabalho, com outros membros da família, inclusivamente com risco de perda de confidencialidade. $\mathrm{O}$ aumento do número de reuniões pode favorecer a exaustão, denominada "fadiga Zoom" (Turner, 2021: 39), o que aliado ao facto de não existirem intervalos entre essas mesmas reuniões não favorece a reflexão,

\footnotetext{
${ }^{5}$ Dr Hans Henri P. Kluge began his term as WHO Regional Director for Europe on 1 February 2020, following his nomination by the WHO Regional Committee for Europe and appointment by the WHO Executive Board.
} 
formulação de novas hipóteses de trabalho e tomada em consideração de ações que deveriam ser implementadas. As emoções como a empatia e a compaixão podem ser mais difíceis no trabalho de forma remota, tendo em conta a forma como nos posicionamos nesses encontros. É fundamental que a equipa encontre espaços de reflexão e de suporte mútuo, através de grupos de WhatsApp ou outros, possibilitando que estes "espaços de pensamento partilhado" (Turner, 2021:41) constituam momentos de apoio mútuo, mas também de desenvolvimento de práticas inovadoras, sendo fundamental que a tecnologia deve ser incorporada na prática do assistente social.

Neste ponto deixamos um conjunto diversificado de indicadores macroeconómicos como contributo para um repensar de práticas e modelos de intervenção e abordagem dos problemas que afetam o bem-estar familiar.

3.1. Abordagens colaborativas e novos métodos de intervenção social na família

O conceito de colaboração refere-se a um termo genérico, um processo de interação que inclui duas atividades, o processo de trabalhar em conjunto para estabelecer uma parceria e o processo de trabalhar em conjunto para atingir os resultados desejados pela parceria (Wilson, 2008). Kanter (1994) definiu a colaboração como "um processo que permite que indivíduos e organizações combinem os seus recursos humanos e materiais de modo a atingirem objetivos que não conseguiriam isoladamente" (Kanter,1994:96 citado por Knott e Scragg, 2016: 165). Por outro lado, o termo multidisciplinar, interdisciplinar ou equipas integradas designa um grupo de profissionais com diferentes formações, a trabalhar em equipa e na gestão do problema, podendo pertencer ou não à mesma organização. Na perspetiva de Taylor e Thoburn (2016) a intervenção de um único profissional não permite o retrato completo das necessidades da criança assim como não responde à complexidade das dificuldades que as famílias vulneráveis experienciam, exigindo assim o trabalho colaborativo em que a intervenção com crianças e famílias é maioritariamente composta por equipas multidisciplinares conjugando diferentes organizações, no sentido de avaliar e responder às necessidades da criança e da família, mas colocando sempre a criança no centro do sistema (Taylor e Thoburn, 2016). A articulação interinstitucional exige uma serie de componentes (Atkinson et al., 2007, citado por Taylor e Thoburn, 2016) incluindo a clarificação de papeis e responsabilidades; assegurar o compromisso a todos os níveis; confiança e respeito mútuo; promoção da compreensão entre organizações; providenciar tempo para desenvolver o trabalho; providenciar formação e alocação adequada de recursos, incluindo tempo. A articulação interinstitucional com crianças vulneráveis é essencial nos diferentes níveis de intervenção, a nível primário, secundário e terciário, conjugada com uma alta qualidade dos serviços prestados por cada disciplina e das equipas multidisciplinares (Taylor e Thoburn, 2016). Os mesmos autores salientam que, por vezes, o risco de o enfoque ser o trabalho colaborativo pode fazer perder de vista a necessidade de uma prática de alta qualidade por parte de cada um dos profissionais que estão envolvidos com os diferentes membros da família e que não se deve esquecer que o trabalho colaborativo não pode ser o fim em si mesmo, mas o meio através do qual se pode atingir uma maior qualidade dos serviços prestados às famílias em situação de vulnerabilidade. Cada profissional traz consigo o conhecimento e competências que derivam da sua formação inicial, qualificação e experiência (Taylor e Thoburn, 2016).

A intervenção com crianças e famílias inclui a assistência prática, mediação e advocacia, o apoio emocional, a assistência no acesso aos serviços de educação ou saúde, o aconselhamento ou terapia para os pais ou crianças nos problemas de saúde mental, adições, trauma ou dificuldades de relações e neste sentido, a família deve constituir-se como parceira na intervenção, nomeadamente na tomada de decisão sobre os serviços prestados. Mesmo que isto não seja possível, os membros da família devem ser informados sobre o que está a acontecer e porquê, estando plenamente envolvidos (Taylor e Thoburn, 2016). Estes autores sublinham que o trabalho com famílias vulneráveis exige a centralidade da ajuda baseada na relação em que a confiança é um elemento fundamental, quer entre os profissionais e com a família; compreender a família como parte do sistema, a partir da qual são delineadas as intervenções; ouvir a perspetiva da criança e da família sobre o que consideram eficaz, tendo em conta as suas experiências anteriores e quais as suas prioridades. A prestação dos serviços tem de ter como base a clareza dos propósitos, comunicando de forma eficaz o que vai ser feito e informando sobre as mudanças que são necessárias, caso a situação de perigo assim o justifique

Nas orientações propostas torna-se fundamental a dimensão ética e os valores que sustentam a intervenção disciplinar e multidisciplinar. Cada profissão apresenta um código de conduta ética que sustenta a prática, podendo ter diferentes designações, mas que encontram semelhanças no seu conteúdo, nomeadamente nas seguintes áreas:

\section{a) Respeito pela pessoa;}

b) Compreensão e respeito pela diversidade quer a nível das famílias como dos profissionais;

c) Requisitos e orientação sobre a confidencialidade e como é que os dados e a informação pessoal devem ser armazenados e mantidos em segurança, e disponibilizada aos outros apenas numa base de "necessidade de saber";

d) Os requisitos para decidir que informação deve ser transmitida e a quem, quando há o risco de dano significativo à criança ou ao adulto; procurar o acordo do sujeito de intervenção a não ser que haja razões claras para que tal não seja possível; 
e) Os requisitos de que não devem ser executadas tarefas que ultrapassem as competências e a formação do profissional;

f) Probidade no acesso aos dados financeiros dos sujeitos ou na gestão de dinheiro e orientação quanto aos procedimentos a ter em caso de ofertas como mostra de gratidão;

g) A necessidade de desenvolvimento profissional contínuo de modo a consolidar um conjunto de conhecimentos e competências relevantes no quadro da intervenção;

h) A importância de providenciar um conjunto de escolhas apropriadas sobre a natureza do serviço e da forma como ele é prestado assim como dar informação adequada possibilitando a decisão sobre essas escolhas;

i) Na procura de um trabalho em parceria com a família ter em atenção da posição desigual entre profissional e sujeito que deriva do domínio do conhecimento profissional (Taylor e Thoburn, 2016).

O modelo colaborativo de intervenção com famílias vulneráveis implica uma aproximação ao trabalho interprofissional, tornando-se importante distinguir multidisciplinaridade e interprofissionalidade. O conceito (multi)disciplinar e (inter)profissional remetem-nos para os conceitos de disciplina e profissional, o primeiro como campo académico e conjunto específico de conhecimentos, o segundo como elemento que integra um grupo ocupacional prestador de serviços (Hood, 2018). O conceito multidisciplinar implica a reunião de representantes de diferentes disciplinas e deve promover o trabalho interprofissional, embora não seja garantia de que tal aconteça (Wilson, 2008: 695) e, nesse sentido, o trabalho interprofessional descreve o trabalho em conjunto de dois ou mais profissionais, implicando aqui algum nível de colaboração entre eles, embora não necessariamente no quadro formal de uma parceria. Uma das configurações do trabalho interprofissional, e talvez a mais frequente na área da intervenção com famílias remete-nos para o trabalho em equipa, englobando uma identidade partilhada pela equipa, interdependência, integração, partilha de responsabilidades e em que as tarefas da equipa são normalmente imprevisíveis, urgentes e complexas (Reeves et al., 2010).

No trabalho em equipa definem-se como valores a perspetiva de suporte de uns em relação aos outros, assim como o respeito pelas competências dos outros e a valorização da sua contribuição. Para isso é exigido que estejam definidos os papeis a desempenhar por cada membro assim como as suas responsabilidades, condição indispensável para que possam partilhar conhecimentos, competências, experiências e recursos na prossecução do bem-estar do sujeito de intervenção. Neste sentido, a comunicação constitui-se como um elemento chave na intervenção, quer para poderem beneficiar de uma aprendizagem mútua, como também discutir as diferenças em função da solução do problema mais adequado. O facto de terem definido objetivos comuns, facilita o debate de opiniões, suportado pela ideia de que todos podem influenciar a tomada de decisões numa partilha de responsabilidades sobre essas mesmas decisões, o que não contradiz a necessidade de uma liderança, mas que envolve os membros, é aberta e assegura a participação de todos. $\mathrm{Na}$ equipa é igualmente importante um espaço de reflexão e avaliação, de modo a poder ser feita uma análise crítica, quer do desempenho como das decisões. Acreditamos que as equipas oferecem a oportunidade de uma aprendizagem coletiva e desenvolvimento, identificando novas formas de trabalhar e, mais importante, implementar soluções inovadoras para os problemas (Hewitt et al., 2014, citado por Hood, 2018).

Reeves et al. (2010) desenvolvem um enquadramento conceptual para o trabalho interprofissional em equipa, definindo quatro domínios, o domínio relacional, processual, organizacional e contextual que incluem um conjunto de fatores que afetam de diferentes formas o trabalho interprofissional:

- O domínio relacional cujos fatores afetam diretamente as relações partilhadas pelas profissões: poder profissional, hierarquia, socialização, composição da equipa, papeis e processos;

- O domínio processual inclui os fatores: tempo e espaço, rotinas e rituais, tecnologias de informação, imprevisibilidade, urgência, complexidade e deslocação de tarefas;

- O domínio organizacional cujos fatores afetam o ambiente organizacional no qual a equipa trabalha: suporte organizacional, representação profissional e o receio de litígios;

- O domínio contextual que se refere à dimensão social, política e económica no qual a equipa está inserida incluindo a cultura, diversidade e género.

Estes fatores, embora apresentados individualmente, estão interrelacionados entre si e têm um impacto significativo no desempenho das equipas, demonstrando igualmente a complexidade do trabalho interprofissional. (Reeves et al., 2020: 70-89).

O modelo colaborativo interprofissional enfatiza as semelhanças entre os grupos profissionais facilitando uma única abordagem ao diagnóstico e definição de objetivos centrados na criança e na família, no reconhecimento de competências partilhadas e propondo uma partilha de compreensão e pontos de vista, situando-se, idealmente, no mesmo nível de hierarquia com boa comunicação e reuniões de equipa. A diferença no trabalho interprofissional é que este foca-se na mutualidade e na colaboração fundamentada na boa comunicação, esbatimento dos limites e trabalho em parceria, enquanto que o trabalho multidisciplinar foca-se nas competências de cada profissional podendo levar a uma fragmentação caso as estratégias de comunicação não funcionem. Mas a interprofissionalidade não procura criar uma abordagem genérica, pelo contrário, exige que cada profissional esteja confiante nas suas 
competências e especialização assim como nas dos seus colegas, de modo a que a prática seja conduzida de um modo não hierarquizado e colegial, como equipa no desenvolvimento das comunidades e na satisfação das verdadeiras necessidades (CAIPE, 2007, citado por Rogers et al., 2017: 157), o que nos leva a refletir nas potencialidades desta abordagem na resposta a um dos desafios da intervenção com crianças e famílias vulneráveis, a necessidade de equilibrar uma intervenção disciplinar eficaz e com qualidade sem perda de uma abordagem multidisciplinar e interinstitucional.

4. Desafios à formação, à investigação e à profissão de Serviço Social no séc. XXI

Na sociedade contemporânea, estamos a assistir a uma cultura organizacional e de serviços que aprofunda a diversidade e a experiência de inclusão, através de uma maior inovação, maior produtividade e benefícios no aumento do envolvimento e satisfação dos trabalhadores. Neste campo há necessidade de investir na aprendizagem e na aquisição de competências digitais numa perspetiva intergeracional, reconhecendo que nem todos dominam as tecnologias e provavelmente alguns grupos de profissionais já não estão motivados para essa aprendizagem dada a sua idade e a sua carreira na empresa.

O processo de transição para uma sociedade digital requer uma reflexão partilhada pelos diferentes atores e agentes que interagem na complexidade do processo. Mas é também necessário refletir os princípios de igualdade e inclusão social no acesso à digitalização, analisando a diversidade do contexto a nível macro, micro e meso.

As tecnologias oferecem oportunidades de aprendizagem sobre diversidade e tópicos de inclusão relevantes. No trabalho e na comunidade, os trabalhadores encontram situações relacionadas com a diversidade e a inclusão, com base numa abordagem inclusiva para responder a estas situações, exigem educação e prática.

A necessidade de que o processo de transição digital seja acompanhado por metodologias adaptadas, centradas nas pessoas (capital humano), orientadas por modelos colaborativos e integrados sustentados por um diálogo social eficaz entre redes e parceiros.

Amanda Taylor-Beswick (2021) discute a educação digital, métodos e práticas, focando-se nas implicações éticas do Covid-19, na obra editada por Turner (2021) A pandemia forçou o Serviço Social a encontrar alternativas digitais à relação face a face o que levou à identificação de alguns problemas nomeadamente falta de conhecimento digital, liderança digital e financiamento. A autora descreve como particularmente relevante a natureza problemática da aceitação e adoção da tecnologia, dificultada pela má gestão das tecnologias de informação e comunicação (TICs) no terreno. Associados a estes factos pode acrescentar-se uma falta de atenção na altura da pré-pandemia às TICs e à digitalização na educação em serviço social, criando um desfasamento nas competências digitais e no desenvolvimento digital na profissão. $O$ facto de a intervenção ocorrer predominantemente num contexto presencial, de relação face-a-face desvalorizou a importância das tecnologias na implementação da prática, assim como o seu ensino, não estando associado ao desenvolvimento do conhecimento profissional ou competências (Taylor, 2017 e Taylor-Beswick, 2019). São distinguidos 3 períodos no serviço social digital, considerando o período pré-pandemia, durante a pandemia e pós-pandemia.

A atual crise global sublinhou as consequências da falta de um avanço digital em Serviço Social, sendo que a urgência para responder à pandemia ofereceu uma pequena oportunidade para o desenvolvimento digital. A autora refere que apesar deste desfasamento já nos anos 70 do século XX se assistiu a alguma preocupação no desenvolvimento daquilo que designa co "consciência sociotécnica, habilidades digitais e práticas" (Beswick,2021:.24). Apoiando-se na perspetiva de Garrett (2005) defende que o ponto de viragem eletrónico para o Serviço Social ocorre muito antes do século XXI. Não pode, no entanto, considerar-se que é um uso sem risco, podendo converter-se em diferentes formas de opressão. Mas a autora conclui que o serviço social está bem posicionado para responder a estas questões, tendo a responsabilidade de resistir às diferentes formas digitais de discriminação e opressão. No futuro os métodos digitais continuarão a ser fundamentais para a continuidade da prática, exigindo uma maior atenção ao futuro digital," mas também às implicações do digital no futuro coletivo, de modo a que a integridade e a eficácia da profissão assim com o valor da humanidade possa ser preservado" (Beswick, 2021: 28).

\section{A intervenção na crise}

A intervenção em situações de crise é um dos pilares básicos da intervenção psicossocial em emergência social. A intervenção em crise é um processo de assistência destinado a ajudar uma pessoa ou família a suportar um acontecimento traumático, de modo a que a probabilidade de enfraquecer os efeitos (estigmas emocionais, danos físicos) seja diminuída e a probabilidade de crescimento (novas competências, perspetivas de vida, mais opções de vida) seja aumentada (Slaikeu,1988).

A intervenção em crise é concebida como uma intervenção a curto prazo, com o objetivo de promover uma mudança construtiva na situação de vida das vítimas e da comunidade o mais rapidamente possível, ao nível da redução do stress na pessoa e na comunidade; prevenir outros possíveis fatores de stress; organizar e mobilizar os pontos fortes (individual, familiar e comunitário); dar apoio psicossocial profissional para facilitar um restabelecimento rápido e mais fácil do nível de funcionamento do que estava presente antes da crise. 


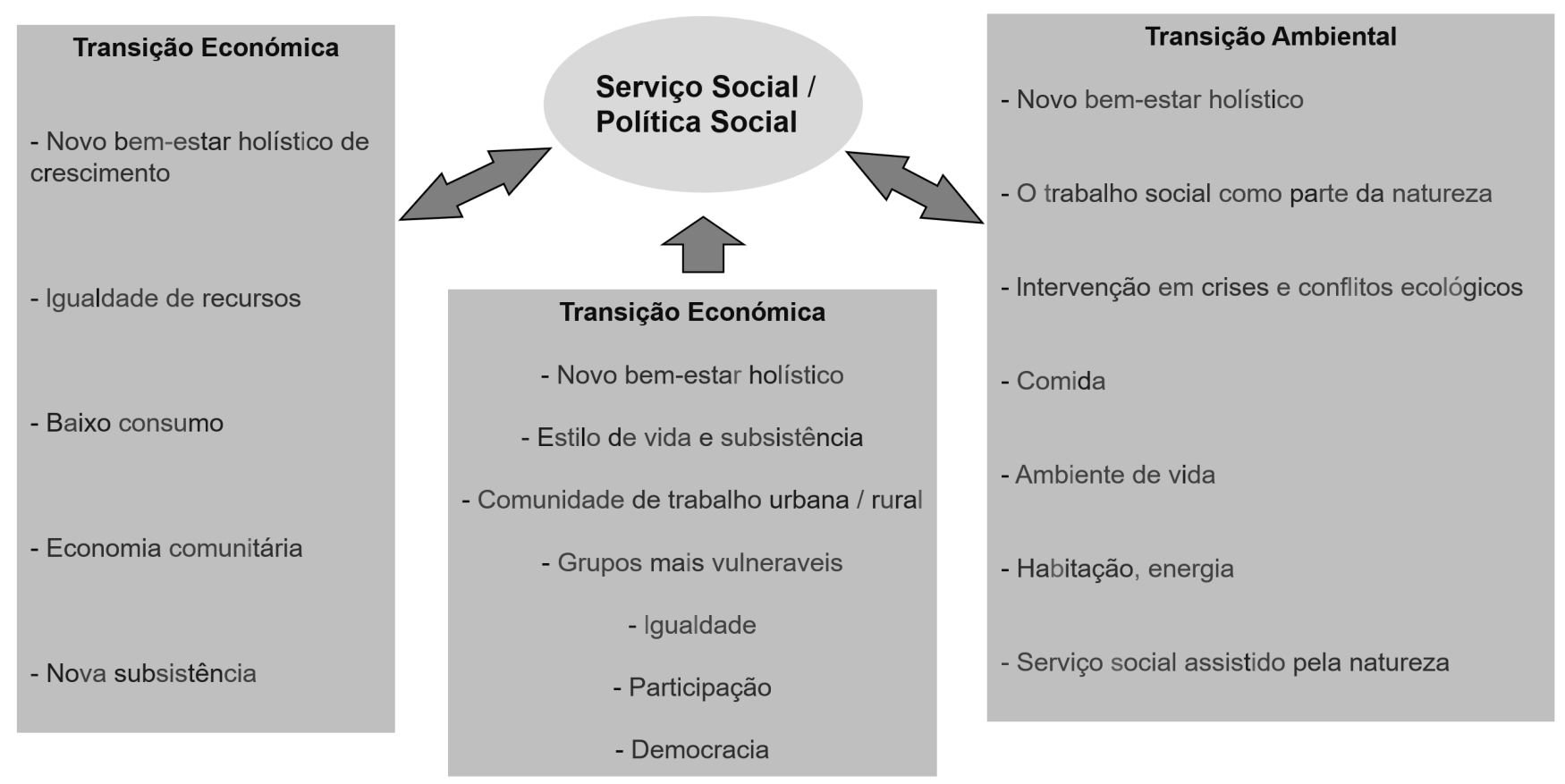

Fonte: Mathies e Narhi (2016).

Referenciamos também outras virtualidades da teoria de intervenção em crise aplicada ao Serviço Social, no que respeita à abordagem direta e com carater de urgência de um problema específico; restabelecimento dos níveis de vida anterior de adaptação ao ambiente em que a pessoa vive; compreender o papel dos fatores ambientais que conduziram a pessoa à crise.

Não podemos esquecer que muitas pessoas que experimentaram situações COVID - 19, têm uma elevada percentagem de possibilidades de sofrer de um distúrbio de Stress Pós-Traumático que que pode não se desenvolver imediatamente. (Relatório IRJ, 2020).

Segundo, Slaikeu, (1988), a intervenção na crise, assume duas fases:

-1a fase de intervenção na crise, carateriza-se pelo apoio e ajuda psicológica/psicossocial imediata, que é oferecida por pessoas que estão próximas do sujeito quando a situação ocorre.

- $2^{\mathrm{a}}$ fase de intervenção na crise, consiste numa breve terapia de crise oferecida por profissionais, cuja função é reduzir a ansiedade, tensão e dar apoio ao sujeito.

Transformação e Transição

Na atualidade vivemos numa sociedade em transição influenciada por diversos fatores tanto estruturais como conjunturais tanto políticos, sociais, económicos e cultu- rais. Transformação, é um conceito muito utilizado pela corrente Germânica (Serviço Social Transformador. Elsen, 2011) e transição é um conceito de discussão mais global sobre o paradigma da transição da cidade, da comunidade (Hopkins, 2011) e como movimento ecossocial. Transição e transformação incorporam neste sentido um forte caráter normativo e pragmático da argumentação que aborda os processos políticos do nível local ao nível global, bem como modelos práticos de mudança de diferentes áreas da vida humana.

Este é um processo que se integra nos objetivos de desenvolvimento sustentável das Nações Unidas, ou seja, a necessidade de reforço do modelo Ecossocial e Ecológico no debate teórico e operativo (prática) sobre a integração destes conceitos nas abordagens do Serviço Social (Mathies e Narhi, 2016; Gray et al., 2012; Dominelli, 2012).

O conceito de Ecossocial possibilita uma combinação de componentes ecológicas, económicas e sociais do desenvolvimento, facilitador de fazer uma interligação entre sustentabilidade social e ecológica. "Uns números crescentes de áreas de ação procuram modelos de transição ecossocial como por exemplo: vida cultural, produção e distribuição de alimentos, governação local, transportes e habitação, Sustentabilidade de comunidades vulneráveis" (Mathies, 2016: 17).

O Serviço Social orienta as suas práticas com base no desenvolvimento dos direitos humanos segundo o princípio de responsabilidade para com a sociedade de forma a assegurar as necessidades civis, políticas, culturais, sociais e económicas das pessoas.

A aplicação de direitos humanos pelos assistentes sociais evidencia-se nas práticas de Intervenção em atos de opressão: opressão refere-se ao uso injusto de autoridade, 
Tabela 1. Intervenção em Crise: Um Modelo Abrangente (Slaikeu,1988)

\begin{tabular}{|c|c|c|}
\hline & $\begin{array}{l}\text { 1a intervenção } \\
\text { Primeira ajuda psicológica }\end{array}$ & $\begin{array}{l}\text { 2a intervenção } \\
\text { Terapia de crise }\end{array}$ \\
\hline Quanto tempo? & Minutos a horas & Semanas a meses \\
\hline Por quem & $\begin{array}{l}\text { Assistentes de linha de frente (família, polícia, igreja, } \\
\text { advogados, médicos, enfermeiros, assistentes sociais, } \\
\text { professores, supervisores, etc.) }\end{array}$ & $\begin{array}{l}\text { Psicoterapeutas e conselheiros (psicólogos, psiquia- } \\
\text { tras, assistentes sociais, conselheiros pastorais e esco- } \\
\text { lares, enfermeiros psiquiátricos, etc.) }\end{array}$ \\
\hline Onde & $\begin{array}{l}\text { Ambientes comunitários: casa, escola, trabalho, } \\
\text { transportes, etc. }\end{array}$ & $\begin{array}{l}\text { Ambientes de terapia/aconselhamento: clínicas, cen- } \\
\text { tros de saúde mental, acesso a instituições, igrejas, } \\
\text { etc. }\end{array}$ \\
\hline Objetivos & Restabelecimento & $\begin{array}{l}\text { Resolução da crise: lidar com o episódio da crise; } \\
\text { integrá-lo na vida; estabelecer abertura/vontade de } \\
\text { enfrentar o futuro. }\end{array}$ \\
\hline Procedimentos & Ajuda psicossocial & Empoderamento da comunidade \\
\hline
\end{tabular}

Fonte: elaboração própria.

ou poder a nível individual ou de grupo. A opressão pode assumir muitas formas: racial, étnica, discriminação, desigualdade de género, etc.

Esta intervenção assegura a efetiva concretização do Art. $1^{\circ}$ da Declaração Universal dos Direitos Humanos "Todo o ser humano tem direito à sua dignidade".

O assistente social fortalece a pessoa ou grupo através do Empowerment, ajudando a compreender a sua experiência de opressão à qual estava sujeita, e a encontrar as respostas corretas. (Saleebey, 2002).

O assistente social é um observador das violações dos direitos humanos, por exemplo, direitos das crianças, exploração do trabalho infantil, prostituição. Assume uma abordagem de Advocacia Social, defendendo os direitos dos grupos vulneráveis, por exemplo, violação de direitos baseados em raça, etnia, gênero, orientação sexual, imigração, religião. A prática do Serviço Social individual ou coletiva (com as famílias), grupos, comunidades, está cada vez mais vinculada aos direitos humanos.

Os assistentes sociais na promoção dos direitos humanos, desenvolvem uma prática, tentando entender a cultura étnica, a experiência das pessoas e a identidade individual, na defesa do princípio da não-discriminação e valorização do princípio da diversidade cultural.

Estratégias para uma intervenção Preditiva

O Serviço Social se pretende projetar novas abordagens e metodologias de intervenção social a médio e a longo prazo deve realizar o diagnóstico Social de nível micro, entendido como valoração e juízo sistemático e interpretativo que fazemos de uma situação determinada, tanto ao nível estrutural como ao nível individual.
Na elaboração deste diagnóstico o Serviço Social deve orientar-se pelos seguintes princípios fundamentais:

- Singularidade de cada pessoa;

- Participação da pessoa em todo o processo;

- Desenvolvimento humano, ou seja, o reconhecimento do processo de desenvolvimento da pessoa e do seu sistema social;

- Diversidade humana, reconhecimento dos diferentes aspetos individuais, culturais e sociais que afetam a vida da pessoa;

- Finalidade da conduta, reconhecer que cada conduta tem um fim e reconhecer a relação com o contexto de vida;

- Transações do sistema, o processo de diagnóstico identifica tanto processos de inadaptação interpessoal como a falta de resposta do meio onde a pessoa vive;

- Limitações e recursos, identificar potencialidades e obstáculos no processo de desenvolvimento social e humano.

Escala Geral de Categorias Diagnósticas de nível macro (Conde, 1998):

- Situação de insatisfação de necessidades, (carência de meios e recursos de resposta às adversidades);

- Dependência Social, (dependência da pessoa de respostas externas para encontrar resposta às suas necessidades); 
- Risco Social, (riscos sociais para a segurança da pessoa e fatores negativos);

- Capacidade de orientação e funcionamento social, Capacidade da pessoa para enfrentar os problemas, na sua vida quotidiana, motivar-se (ganhar autoestima) autonomizar-se, decidir e atuar.

Para a concretização deste diagnóstico de nível macro preditivo devemos selecionar desenhos de ações estratégicas em Serviço Social baseadas no conhecimento da realidade social, realizando:

- Programas de sensibilização para a população sobre necessidades das pessoas, promovendo assim uma mudança das perceções de vida destes cidadãos;

- Realizar programas de experimentação com a população;

- Realizar programas de informação com os meios locais de comunicação social;

- Gerar micro espaços sociais de promoção de sociabilidade comunitária e de capacitação de programas de diálogo, "self help"e outros.

Na aplicação deste tipo de diagnóstico necessitamos de novas abordagens baseadas em metodologias de investigação ação colaborativa mais centradas na realidade do quotidiano da intervenção dos serviços dando relevo à fenomenologia através do reconhecimento do sujeito como parceiro na ação, transformando o espaço institucional num laboratório de análise da realidade social.

O Serviço Social Internacional tem vindo a desenvolver nas últimas duas décadas dois modelos de prática profissional, denominados de Evidence Based Practice (EBP) e Practice-based research (PBR), que apresentamos sumariamente (Dodd e Epstein, 2012).

Tabela 2. «Investigação - Intervenção» «Intervenção - Investigação»:

\begin{tabular}{|l|l|}
\hline \multicolumn{1}{|c|}{ EBP - Evidence Based Practice } & PBR -Practice-Based Research \\
\hline Prática indutiva & Prática dedutiva \\
\hline Métodos quantitativos e qualitativos & Métodos qualitativos \\
\hline $\begin{array}{l}\text { Sistematizar e rever a literatura } \\
\text { sobre o problema (pesquisa docu- } \\
\text { mental) }\end{array}$ & $\begin{array}{l}\text { Identificação dos problemas } \\
\text { dos sujeitos de atenção }\end{array}$ \\
\hline Que permita fazer investigação & Caracterização do sujeito \\
\hline $\begin{array}{l}\text { Desenhar uma intervenção informa- } \\
\text { da pela investigação }\end{array}$ & Definir intervençães \\
\hline & $\begin{array}{l}\text { Elaborar um plano de inter- } \\
\text { venção }\end{array}$ \\
\hline & Avaliação \\
\hline
\end{tabular}

Fonte: elaboração própria.
Proteção de dados e princípios ético-deontológicos

Segundo, Ricou (2014), a ética é o modo de ser ou carácter do indivíduo. Este carácter é o resultado de um conjunto de experiências de vida, que pode ser definido como a personalidade expressa, são os comportamentos que são visíveis e possíveis avaliar pelos outros. Quando esta avaliação é satisfatória, o indivíduo continua a repetir, o que o torna um hábito, assim este hábito faz parte do "ethos" do indivíduo. A ética é um conjunto de normas que guiam a conduta do indivíduo, informando-o sobre o que é permitido e o que é interdito (Dias, 2004).

A ética das profissões define o conjunto dos deveres e das responsabilidades ligadas a cada profissão. A prática profissional e os códigos deontológicos têm de ter em consideração a ética (Dias, 2004), nomeadamente o respeito pelos direitos e dignidade humana, entendida como "[...] um ser único, semelhante a todos os outros, que tenham os mesmos direitos e deveres, também é diferente de todos os demais: a importância concebida à sua dignidade intrínseca, quaisquer que seja as circunstâncias que se encontrem e leva em conta na qualidade de sujeito capaz de decidir e participar" (Robertis, 2003: 46-47). A autodeterminação é um outro princípio ético em Serviço Social, definida como o agir sobre as escolhas.

Os assistentes sociais na intervenção com famílias devem informar todos os sujeitos, independentemente da idade, do nível de compreensão e das suas capacidades, para que possa ter a oportunidade de fazer as suas escolhas ${ }^{6}$.

Associamos á autodeterminação do sujeito o chamado consentimento livre e informado, dado que só a partir das informações prestadas "sobre a natureza da relação profissional, a natureza da intervenção, autoridade delegada no profissional e os limites da autoridade competente, que as decisões que o cliente pode fazer e que decisões do profissional bem-estar infantil vai fazer"7.

De acordo com as Diretrizes do Comité de Ministros do Conselho da Europa (CMCE), "o respeito pela dignidade é uma exigência fundamental dos direitos humanos, [...] cada criança é um ser humano único e precioso, e, como tal, a sua dignidade individual, as suas necessidades especiais, os seus interesses e a sua privacidade devem ser respeitados e protegidos (Conselho da Europa, 2013: 57).

$\mathrm{Na}$ atualidade o princípio da confidencialidade e privacidade, assume particular atenção no quadro do regulamento geral de proteção de dados. A privacidade está relacionada com a vida privada e a intimidade do individuo, entende-se que toda a informação relevada numa relação profissional só possa ser divulgada quando autorizada pelos pacientes/clientes, caso contrário deve ser mantido (Senivongse e Oliveira, 2009). Já a confidencialidade "diz respeito à informação que é recolhida ou realizada pelo psicólogo. Ele inclui a obrigação específica, tanto ética e legal, que a informação privada deve ser mantida com se-

\footnotetext{
${ }^{6}$ Illinois Department of Children and Family Services, 2010.

${ }^{7}$ Illinois Department of Children and Family Services, 2010: 9
} 
gurança e nunca revelou a outras pessoas, voluntariamente ou em resposta a um pedido formal, a menos que sejam satisfeitas determinadas condições" (Nogy, 2014: 106). A confidencialidade pode ser quebrada em dois casos, quando constitui perigo para si próprio e quando constitui perigo para os outros (Dén-Nagy, 2014).

\section{Conclusão}

A resiliência é o conceito mais apelativo nestes períodos de crise, enquanto capacidade individual para fazer face às adversidades inerentes ao contexto pandémico, tem sido referida como variável protetora de sintomas de ansiedade, depressão e mesmo de stress pós-traumático, quer na população geral (Ran et al., 2020). No contexto mais alargado das relações interpessoais, tem sido investigada a importância do suporte social como fator protetor da saúde mental (Ran, Xuyu, Ying et al., 2020).

A importância de um novo modelo ético-teórico na formação profissional torna-se evidente quando cada profissão coloca problemas que respeitam um conjunto de problemas sociais da população sob ação profissional, nomeadamente:

- Aborto, planeamento familiar, saúde, ação social, educação, justiça social, discriminação social, exclusão social, etc.

Precisamos de repensar a nossa ética, juntando isto à política e à profissão, o que nos leva a repensar a prática profissional como intervenções que têm como horizonte a construção de sujeitos coletivos integrados numa nova hegemonia na realidade social. A deontologia deve evitar que a conduta profissional se torne numa mera declaração de boas intenções, devendo assumir a sua responsabilidade cívica e política, com o objetivo de construir novas propostas coletivas diferentes das atuais.

Construir uma nova prática profissional com base nos princípios de:

- Prática profissional numa dimensão local e global;

- A globalização económica / social;

- O novo conceito de trabalho e emprego;

- O papel do Estado e da sociedade civil;

- Uma nova ideia de desenvolvimento sustentável à escala global.

SEREMOS PRO-ATIVOS, AGENTES DE MUDANÇA E INTERVENTORES PREPARADOS PARA A TRANSIÇÃO SUSTENTÀVEL DA SOCIEDADE PARA O BEM-ESTAR GLOBAL DE TODAS AS PESSOAS
Bibliografia

ALARCÃO, M. e Gaspar M. (2007): "Imprevisibilidade familiar e suas implicações no desenvolvimento individual e familiar", Paidéia (Ribeirão Preto), 17 (36), pp. 89-102. https://doi.org/10.1590/S0103863X2007000100009.

APCC (Associação de Paralisia Cerebral de Coimbra) (2019): Projeto Erasmust, Life.

ATKINSON, M., JONES, M. e LAMONT, E. (2007): Multi-agency Working and its Implications for Practice: a review of the literature. Disponível em: www.nfer.ac.uk/publications/MAD01/MAD01_home.cfm.

BANCO CENTRAL EUROPEU (2020): Relatório, Macroeconómico BCE para a zona euro/ setembro de 2020.

BODDEN, Denise e DEKOVIC, Maja Dekovic (2016): "Multiproblem families referred to youth mental health: What's in a name?", Family Process, 55, pp. 31-47.

CAIPE (Centre for the Advancement of Interprofessional Education), www.caipe.org.uk.

CASADO DE STARITZKY, Tatiana; RIERA ADROVER, Joan e CARDONA, Josefa (2020): "Social Work with Families in Special Distress: Collaborative Practices", Social Sciences, 9 (7), 121. https://doi.org/10.3390/ socsci9070121.

CONDE, R. (1998): Trabajo social experimental. Valencia, Tirant lo Blanch.

CHAGAS, Eveline (2014): Trabajo Social con Familias: Un Estudio Comparado Sobre la Intervención en los CRAS de Forteza-CE-Brasily los CSS de Barcelona-ES. Ph.D. thesis, Universitat Autònoma de Barcelona. Disponível em: https://www.tesisenred.net/handle/10803/134823.

COULSHED, Veronica e ORME, Joan (2006): Social Work Practice (4a ed). Londres, Palgrave Macmillan.

DE ROBERTIS, Cristina (2003): Fundamentos del trabajo social: Ética y metodología. Valencia, Publicacions de la Universitat de València.

DÉN-NAGY, Ildikó (2014): "A Double-Edged Sword? A Critical Evaluation of the Mobile Phone in Creating Work-Life Balance", New Technology, Work and Employment, 29 (2), pp. 193-211. Doi: https://doi. org/10.1111/ntwe.12031.

DIAS, Maria Olívia (2004): "Reflexões sobre a ética no quotidiano da profissão", Gestão e Desenvolvimento, 12, pp. 81-103. Doi: https://doi. org/10.7559/gestaoedesenvolvimento.2004.106.

DODD, Sarah-Jane e EPSTEIN, Irwin (2012): Practice-Based Research in Social Work: A Guide for reluctant researchers. New York, Routledge.

DOMINELLI, Lena (2012): "Green Social Work: From Environmental Crises to Environmental Justice", British Journal of Social Work, 42 (8), pp. 1636-1637. Doi: https://doi.org/10.1093/bjsw/bcs183.

EVENBOER, K. Els; REIJNEVELD, Sijmen A. e JANSEN, Danielle E. M. (2018): "Improving care for multiproblem families: Context-specific efectiveness of interventions?", Children and Youth Services Review, 88, p. 274-285. Doi: https://doi.org/10.1016/j.childyouth.2018.03.024

FROST, Nick e DOLAN, Pat (2012): "The theoretical foundations of family support work", em Martin Davies, Martin (ed,), Social Work with Children and Families. Basingstoke, Palgrave Macmillan, pp. 40-49.

GARRETT, P. M. (2005): “Social Work's 'Electronic Turn': Notes on the Deployment of Information and Communication Technologies in Social Work with Children and Families", Critical Social Policy, 25 (4), pp. 529-553.

GRAY, C. e MACBLAIN, S. (2012): Learning theories in childhood. Londres, Sage.

HEWITT, G.; SIMS, S. e HARRIS, R. (2014): “Using Realist synthesis to understand the mechanisms of interprofessional teamwork in health \& social care" CAIPE. https://www.caipe.org/resources/publications/hewittg-simss-harris-r-2014-using-realist-synthesis-understand-mechanisms-interprofessional-teamwork-health-social-care.

HOOD, Rick (2018): Complexity in Social Work. London, Sage Publications IMBER-BLACK, Evan (2000): Familias y Sistemas Amplios. Buenos Aires, Amorrortu. 
INSTITUTO NACIONAL DE SAÚDE DR. RICARDO JORGE (2021): SM-COVID19 - Saúde mental em tempos de pandemia - relatório final. https://www. insa.min-saude.pt/sm-covid19-saude-mental-em-tempos-de-pandemia-relatorio-final/.

INTRUM (2021): EUROPEAN Consumer Payment Report 2020 Special Edition White Paper. https://www.intrum.com/publications/europeanconsumer-payment-report/ecpr-2020-special-edition-whitepaper/.

KANTER, RM (1994): “Collaborative advantage: The art of alliances”, Harvard Business Review, July-August, pp. 96-108.

KNOTT, C. e SCRAGG, T. (2016): Reflective Practice in Social Work. Londres, Sage.

MATTHIES, Aila-Leena e NARHI, Kati (2016): The Ecosocial Transition of Societies. The contribution of social work and social policy. Londres, Taylor and Francis.

MATTHIES, Aila-Leena (2016): Conceptual and historical analysis of ecological social work. Re-visioning social work with individuals, collectives, and communities: social work research. Program Book \& Book of Abstracts. 5th European Research Conference of Social Work, Ljubljana 22 24. 4. 2015, p. 167.

McCORMACK, Jess (2012): "Family support in practice", em Davies, Martin (ed.), Social Work with Children and Families. London, Palgrave Macmillan.

PAES MAMEDE, Ricardo (coord.); PEREIRA, Mariana e SIMÕES, António (2020): Portugal: Uma análise rápida do impacto da COVID-19 na economia e no mercado de trabalho. Organização Internacional do Trabalho. https://www.ilo.org/wcmsp5/groups/public/---europe/---rogeneva/---ilo-lisbon/documents/publication/wcms_754606.pdf.

RAN, Li; XUYU, Chen; YING, Wang; WENWEN, Wu; ZHANG, Ling e XIAODONG, Tan (2020): "Risk Factors of Healthcare Workers with Coronavirus Disease 2019: A Retrospective Cohort Study in a Designated Hospital of Wuhan in China", Clinical Infectious Diseases, 71 (16), pp. 2218-2221. Doi: https://doi.org/10.1093/cid/ciaa287.

REEVES, Scott et al. (2010): Interprofessional Teamwork for Health and Social Care. Londres, Wiley-Blackwell.

RODRIGO, María José et al. (2008): Preservación Familiar. Madrid, Ediciones Pirámide.

ROGERS, Michaela et al. (2017): Developing Skills for Social Work Practice. Londres, Sage.

RICOU, M. (2014): A ética e a deontologia no exercício da psicologia [Ethics and deontology in the practice of psychology]. Lisboa, Ordem dos Psicólogos Portugueses.

SALEEBEY, Dennis (2002): The strengths perspective in social work practice. Boston, Allyn and Bacon (3a Ed. N. York).

SENIVONGSE, Twittie e OLIVEIRA, Rui (eds.) (2009): Distributed Applications and Interoperable Systems. 9th IFIP WG 6.1 International Conference, DAIS 2009, Lisbon, Portugal, June 9-12, 2009, Proceedings. Berlin/Heidelberg, Springer.

SHAMAI, Michal; MOIN, Victor e SHARLIN, Schlomo (2003): "Poverty in the "promised land": Therapeutic intervention with immigrant caucasus families in Israel", Families in Society, 84, pp. 559-570.

SLAIKEU, K. A., Pearson, J. e Thoennes, N. (1988): "Divorce mediation behaviors: A descriptivesystem and analysis", em Jay Folberg e Ann Milne (eds.), Divorce mediation. Theory and practice. Nova York, The Guilford Press, pp. 475-495.

SOUSA, Liliana (2005): Famílias Multiproblemáticas. Coimbra, Editora Quarteto.

SOUSA, Liliana e COSTA, Tania (2010): "The multi-professional approach: Front-line professionals' behaviours and interactions", International Journal of Social Welfare, 19, pp. 444-454.

TAYLOR, J. e THOBURN, J. (2016): Collaborative Practice with vulnerable children and their families. Londres, Routledge.

TAYLOR-BESWICK, Amanda M. L. (2017): "Social Work and Digitalisation: Bridging the Knowledge Gap", Social Work Education: The International Journal, 36 (8), pp. 869-879.

TAUSENDFREUND, Tim; KNOT-DICKSCHEIT, Jana; SCHULZE, Gisela; KNORT, Erik J. e GRIETENS, Hans (2016): “Families in multi-problem situations:
Backgrounds, characteristics and care services", Child \& Youth Services, 37, pp 4-22.

TAYLOR-BESWICK, Amanda M. L. (2019): Examining the Contribution of Social Work Education to the Digital Professionalism of Students in Readiness to Practice in the Connected Age. Ph.D. thesis, University of Central Lancashire. https://ethos.bl.uk/OrderDetails.do?uin=uk. bl.ethos.784597.

TURNER, Denise (ed.) (2021): Social Work and Covid-19: Lessons for Education and Practice. St. Albans, Critical Publishing

UNICEF (2020): Responding to COVID-19. Annual Report 2020. https:// www.unicef.org/media/100946/file/UNICEF\%20Annual\%20Report\%202020.pdf.

VAN DEN ELSEN, Peter J. (2011): “Expression regulation of major histocompatibility complex (MHC) class I and class II encoding genes", Frontiers in Immunology: Molecular Innate Immunity, 2 [48]. https://doi. org/10.3389/fimmu.2011.00048.

WILSON, Kate et al. (2008): Social Work an introduction to contemporary practice. Essex, Pearson Education Limited. 